\title{
$S$-Adenosyl methionine synthetase 1 limits fat storage in Caenorhabditis elegans
}

\author{
Madeleine Ehmke $\cdot$ Katharina Luthe • \\ Ralf Schnabel · Frank Döring
}

Received: 3 December 2013/ Accepted: 27 January 2014/Published online: 8 February 2014

(C) Springer-Verlag Berlin Heidelberg 2014

\begin{abstract}
Cytosolic lipid droplets are versatile, evolutionarily conserved organelles that are important for the storage and utilization of lipids in almost all cell types. To obtain insight into the physiological importance of lipid droplet size, we isolated and characterized a new $S$-adenosyl methionine synthetase 1 (SAMS-1)-deficient Caenorhabditis elegans mutant, which have enlarged lipid droplets throughout its life cycle. We found that the sams-1 mutant showed a markedly reduced body size and progeny number; impaired synthesis of phosphatidylcholine, a major membrane phospholipid; and elevated expression of key lipogenic genes, such as dgat-2, resulting in the accumulation of triacylglyceride in fewer, but larger, lipid droplets. The sams-1 mutant store more than $50 \%$ (wild type: $10 \%$ ) of its intestinal fat in large lipid droplets, $\geq 10 \mu \mathrm{m}^{3}$ in size. In response to starvation, SAMS-1 deficiency causes reduced depletion of a subset of lipid droplets located in the anterior intestine. Given the importance of liberation of fatty acids from lipid droplets, we propose that the physiological function of SAMS-1, a highly conserved enzyme involved in one-carbon metabolism, is the limitation of fat storage to ensure proper growth and reproduction.
\end{abstract}

Electronic supplementary material The online version of this article (doi:10.1007/s12263-014-0386-6) contains supplementary material, which is available to authorized users.

M. Ehmke · F. Döring ( $₫)$

Department of Molecular Prevention, Institute of Human

Nutrition and Food Sciences, University of Kiel,

Heinrich-Hecht-Platz 10, 24118 Kiel, Germany

e-mail: sek@molprev.uni-kiel.de

K. Luthe $\cdot$ R. Schnabel

Department of Developmental Genetics, Institute of Genetics,

TU Braunschweig, Spielmannstr. 7, 38106 Brunswick, Germany
Keywords One-carbon metabolism - Lipid homeostasis . Lipid droplet $\cdot$ Forward mutagenesis $\cdot$ Nutrigenomics

\section{Introduction}

Lipid droplets (LDs) have been identified in a wide range of species, from bacteria to humans, and are present in the cytosol of almost all eukaryotic cell types. LDs contain a hydrophobic core, predominantly composed of triacylglycerols (TAGs) and sterol esters. The core is surrounded by a phospholipid monolayer containing phosphatidylcholine (PC) and phosphatidylethanolamine (PE), which are the main surface phospholipids (PLs) in LDs (Bartz et al. 2007). Several hundred proteins are associated with the LD surface or are embedded in the LD membrane. These include structural proteins, such as perilipin and CIDE proteins, which are critical regulators of lipid storage and utilization; SNARE proteins, which mediate vesicle fusion; and key enzymes involved in PL and TAG synthesis (Farese and Walther 2009). The decoration of LDs with such diverse proteins is the basis of their versatile functions. LDs are important for lipid homeostasis (Farese and Walther 2009), virus replication (Herker and Ott 2011), and transient storage of hydrophobic proteins and histones (Anand et al. 2012; Li et al. 2012).

The most prominent and evolutionarily conserved function of LDs is the storage and utilization of neutral lipids. LDs regulate intracellular lipid homeostasis and protect cells against lipotoxicity (Farese and Walther 2009). Under conditions of lipid overload, the number and/ or size of LDs increases to enhance lipid storage capacity (Krahmer et al. 2011; Kuerschner et al. 2008). During times of increased energy demand, including cell growth or starvation, fatty acids are effectively delivered from LDs 
(Zechner et al. 2009). These fatty acids are used for $\beta$-oxidation, biogenesis of membrane lipids, and synthesis of lipoproteins, steroids, and other lipid mediators (Fujimoto and Parton 2011; Walther and Farese 2012). Lipid hydrolysis is mediated by LD-associated lipases, such as adipose triglyceride lipase (ATGL) (Zimmermann et al. 2004). Studies in mice, yeast, flies, and nematodes using mutants deficient in the ATGL homologs of these species have shown that inefficient lipolysis of LDs is associated with proteolytic stress on many organs, a delay in cellcycle entry, embryonic lethality, and reduced motility and survival during starvation (Gronke et al. 2005).

During the last decade, several genes involved in the synthesis, storage, and utilization of lipids have been identified in Caenorhabditis elegans and shown to be highly conserved (Zhang et al. 2013). C. elegans stores fat in intestinal and hypodermal LDs (Hellerer et al. 2007). Both mutant analysis and RNA interference (RNAi) screens in $C$. elegans have revealed evolutionarily conserved genes linked to LD size (Zhang et al. 2013). Most of these genes encode proteins that participate in lipogenesis, B-oxidation, phospholipid synthesis and binding, and the intracellular transport of fatty acids. In the present study, we isolated a new $C$. elegans mutant that has enlarged lipid droplets throughout its life cycle. Identification of the mutation that causes this phenotype and characterization of the mutant demonstrated that the $S$-adenosyl methionine synthetase 1 (SAMS-1) protein, a conserved, central enzyme involved in one-carbon metabolism, is necessary to maintain homeostasis between PC synthesis, lipogenesis, LD size, and lipolysis efficiency in limiting fat storage.

\section{Materials and methods}

Worm strains and culture

The Bristol N2 strain was a kind gift of John Sulston (1989). The Hawaiian CB4856, sams-1 (ok3033) (made by OMRF Knockout Group) and VS20 (hjIs67) (Zhang et al. 2010) strains were obtained from the Caenorhabditis Genetics Center (Minneapolis, MN, USA). The $480 \mathrm{bp}$ deletion in $o k 3033$ covers half of the large exon 3 of sams1 leading to a truncated protein of 195 amino acid residues (wild type: 403 residues). As a consequence, the SAMS-1 mutant protein contains a truncated second functional domain and lacks the third functional domain. Because the intact that first functional domain of the mutant protein may have residual activity ok3033 is most likely a strong hypomorph but not a null allele. The nematodes were cultured at $15^{\circ} \mathrm{C}$ on nematode growth medium (NGM) agar plates seeded with Escherichia coli var. OP50 as the food source. For all experiments, gravid adult worms were treated with hypochlorite to obtain synchronized populations.

EMS mutagenesis and isolation of mutant $t 3210$

Ethyl methanesulfonate mutagenesis was performed according to Brenner (Brenner 1974). A screen for temperature sensitive embryonic lethal mutants was performed in the laboratory of Ralf Schnabel (TU Braunschweig, Germany) as follow: (a) Mutagenesis: The P0 was mutagenized with EMS (20 $\mu \mathrm{l}$ in $1 \mathrm{ml} \mathrm{M9})$ and distributed on large NGM plates (25-30 worms per plate) for recovery. The F1 generation was picked on 90 large $(90 \mathrm{~mm})$ plates (25-30 worms each). We estimated to get an offspring of around 2,500-3,000 F2 worms per plate after mutagenesis of the P0. (b) Worm sorting: We used the worm sorter (COPAS, Union Biometrica) to single worms based on their larval stage (L1 to Adult stage). We performed four independent screens. In each screen, we cloned $\sim 115.000$ L4 larvae in 96-well plates. These plates were incubated at permissive temperature $\left(15^{\circ} \mathrm{C}\right)$ for 8 days and then replicated with a Biomek FX (Beckman Coulter). These replica plates were incubated at restrictive temperature $\left(25^{\circ} \mathrm{C}\right)$ for 8 days. (c) Screen: After the incubation at restrictive temperature, we analyzed the wells by eye for lethality. Afterward, we combined all positive worms from the $15^{\circ} \mathrm{C}$ plates (F2) in new 96-well plates and re-tested them for embryonic lethality. Finally, all positive candidates were collected on small NGM plates and re-tested for temperature sensitivity one more time before the phenotypic analysis was undertaken. The phenotypes of 1,669 mutants were assigned to seven main and 27 subclasses (Ralf Schnabel and coworkers, unpublished). The mutant $t 3210$ was chosen because the embryo of this strain contained large "bubbles," and this phenotype was considered interesting. Temperature sensitivity of $t 3210$ was lost during outcrossing.

Identification of a mutation in the sams-1 gene

Hermaphrodites of the mutant $t 3210$ were outcrossed five times with $\mathrm{N} 2$ males to reduce background mutations, after which $t 3210$ hermaphrodites were crossed with males of the polymorphic Hawaiian strain CB4856. F2 progeny displaying the "bubble" phenotype represented recombinants between Hawaiian and Bristol N2 chromosomes. The progeny (F3 and subsequent generations) of $45 \mathrm{~F} 2$ recombinants were used to generate a recombinant DNA pool. This DNA pool was subjected to the one-step wholegenome sequencing and SNP mapping (WGS/SNP mapping) procedure (Davis et al. 2005; Doitsidou et al. 2010). Sequencing was conducted on the Illumina GA2 sequencing platform. The WGS dataset was analyzed by the Oliver 
Hobert laboratory (Columbia University, New York, USA). The obtained sequences were aligned to the WS220 release of the $C$. elegans genome. To verify the $\mathrm{C} \rightarrow \mathrm{T}$ transition at position X: 11966380, we PCR-amplified $742 \mathrm{bp}$ of genomic DNA from $t 3210$ and N2 worms harboring the locus of interest within the sams-1 gene. The primers used for amplification were CCTTTTCACCAGTGAATCTGTG and CCTTCTTGATAACATCAGCGAG. The resultant PCR products were Sanger sequenced by Eurofins MWG Operon (Ebersberg, Germany) using their value read service. The PCR products were also subjected to RFLP analysis, as the $\mathrm{C} \rightarrow \mathrm{T}$ transition at position $\mathrm{X}: 11966380$ alters the recognition site of the Fnu4HI restriction enzyme. Both the sequencing and RFLP analyses confirmed the mutation in sams-1.

Survival rates of worms exposed to arsenite

Synchronized L4 worms were transferred to small NGM agar plates containing $4 \mathrm{mM}$ sodium arsenite (Sigma Aldrich $^{\circledR}$, Steinheim, Germany). Worms transferred to standard NGM agar plates were used as controls. Each experiment comprised 3 stress and 3 control plates. Ten worms were cultivated per plate. To calculate survival rates, the worms were scored for viability after $24 \mathrm{~h}$ of sodium arsenite exposure. A worm was scored as dead when it did not respond to a mechanical stimulus. The experiment was performed 3 times. RNAi experiments targeting sams-1 and gcs- 1 were conducted as internal controls. In these experiments, N2 worms were fed individual $E$. coli strains expressing dsRNA for the respective target gene. The empty vector L4440 served as a control. The E. coli RNAi strains were derived from the Ahringer RNAi library (Kamath and Ahringer 2003). To induce gene knockdown in these worms, RNAi bacteria were grown in LB medium containing $50 \mu \mathrm{g} / \mathrm{ml}$ ampicillin and $5 \mu \mathrm{g} / \mathrm{ml}$ tetracycline and then seeded onto RNAi plates (NGM supplemented with $50 \mu \mathrm{g} / \mathrm{ml}$ ampicillin and $2.5 \mathrm{mM}$ IPTG). Eggs were scattered on the RNAi plates and allowed to develop. At the L4 stage, the worms fed the RNAi constructs were transferred to RNAi/+ sodium arsenite or RNAi/- sodium arsenite plates and scored for viability.

Analysis of body size, hatching rates, and progeny numbers

Based on the analysis of microscopy images, the body volume of the worms was calculated from the area and perimeter using an adapted cylinder volume formula (Salomon et al. 2009). To determine the number of progeny, L4 larvae (P0) of each strain were individually placed on small NGM agar plates and screened for the production of viable progeny during the entire reproductive phase. To prevent intermixing of $\mathrm{F} 1$ and $\mathrm{F} 2$ progenies, adult $\mathrm{P} 0$ worms were transferred to fresh plates at intervals of $48 \mathrm{~h}(\mathrm{~N} 2)$ or $72 \mathrm{~h}$ (sams-1 mutants). The viable F1 progeny were scored at the L4 stage. For each strain, 10 individual worms were analyzed in two independent experiments.

\section{Starvation experiments}

Synchronized worms were grown on NGM agar plates until the L4 stage before harvesting and washing 3 times with M9 buffer. As a control group ( $0 \mathrm{~h}$ of starvation), one-third of each population was immediately collected into 0.5-ml tubes in clusters of 3,000 worms via COPAS Biosort flow cytometry and stored at $-80{ }^{\circ} \mathrm{C}$ until further processing. To induce starvation, residual worms from each population were split into 2 aliquots and cultivated in M9 buffer supplemented with an antibiotic (dilution: 1:100, Cell Culture Guard, AppliChem) in 15-ml Falcon tubes on a nutator mixer. After 24 and $48 \mathrm{~h}$, the respective starvation groups were collected in the same manner as control samples, and the samples were used for colorimetric TAG and protein quantification. An aliquot of worms from each starvation condition $(0,24$, or $48 \mathrm{~h}$ of starvation) was separated and subjected to fixative BODIPY 493/503 staining to analyze the number and size of lipid droplets.

\section{BODIPY $^{\mathrm{TM}} 493 / 503$ staining and fluorescence imaging}

To visualize fat storage in eggs, synchronized L4 larvae, and adult worms, vital BODIPY ${ }^{\mathrm{TM}} 493 / 503$ (Invitrogen, Darmstadt, Germany) staining was performed as previously described (Klapper et al. 2011). Briefly, freshly harvested worms were washed 3 times with M9 buffer and incubated in $500 \mu \mathrm{l}$ of BODIPY ${ }^{\mathrm{TM}}$ 493/503 solution $(6.7 \mu \mathrm{g} / \mu \mathrm{l}$ M9 buffer) for $20 \mathrm{~min}$. After 3 washing steps in M9, the worms were anesthetized in sodium azide (2\%) for 2 min on ice, washed again, and immediately subjected to microscopy. BODIPY ${ }^{\mathrm{TM}}$ 493/503 fluorescence was visualized using an Axio Imager. Z1 microscope equipped with a 38 HE filter (excitation: BP 470/40, beamsplitter: FT 495, emission: BP 525/50), coupled with an apotome sectioning system (ApoTome.2, Zeiss). Single-plane images were captured using an AxioCam MRm (Zeiss).

Analysis of the number and size of lipid droplets

To determine the number and size of lipid droplets, the BODIPY $^{\mathrm{TM}}$ 493/503 fixative fat staining method was applied as previously described (Klapper et al. 2011). Briefly, freshly harvested worms were washed with M9 and fixed in a $4 \%$ paraformaldehyde solution for $15 \mathrm{~min}$. After 
3 freeze/thaw cycles in liquid nitrogen, the worms were washed again to remove paraformaldehyde and incubated in BODIPY ${ }^{\mathrm{TM}} 493 / 503$ staining solution $(1 \mu \mathrm{g} / \mu \mathrm{l})$ for $1 \mathrm{~h}$, followed by 3 final washing steps. BODIPY ${ }^{\mathrm{TM}}$ 493/503stained LDs localized to the anterior or posterior intestine were imaged via 3D fluorescence microscopy using an Axio Imager Z1 microscope and a plan-apochromat $40 \times / 1.3$ oilimmersion objective. The apotome sectioning system was employed to collect z-stacks with a step size of $1 \mu \mathrm{m}$. The Z-stacks comprised 10-25 plane images (format: $223 \times 168 \mu \mathrm{m} ; 692 \times 520$ pixels), depending on the strain and developmental stage. Images were captured using an AxioCam MRm (Zeiss). ImageJ software (version $1.47 \mathrm{~h}$ ) and the $3 \mathrm{D}$ object counter plugin were used to analyze the z-stacks. BODIPY ${ }^{\mathrm{TM}}$ 493/503-positive structures were automatically identified via adaptive thresholding, and the volume of each droplet was evaluated by summing the voxels per droplet. Further calculations of the total lipid droplet number, mean lipid droplet size, and total lipid droplet volume were performed using Microsoft Excel (version 2003). At least 10 images per strain, region, and developmental stage were analyzed from 3 independent experiments.

\section{Colocalization experiments}

sams-1(t3210) mutants were crossed with VS20 (hjIs67) males expressing an ATGL-1::GFP fusion protein [atgl1p::atgl-1::GFP]. F2 progeny showing the "bubble" phenotype as well as GFP fluorescence were used for colocalization analyses. In these experiments, t3210; atgl1p::atgl-1::gfp worms were vitally stained with LipidToxRed (1:200; Invitrogen) in a similar manner to vital BODIPY 493/505 ${ }^{\mathrm{TM}}$ staining. GFP fluorescence was visualized using a 38HE filter (excitation BP 470/40; beam splitter FT 495; emission BP 525/50), and LipidToxRed fluorescence was visualized with a $43 \mathrm{HE}$ filter (excitation BP 550/25; beam splitter FT 570; emission BP 605/70). Images were captured with an AxioObserver D1 inverted microscope equipped with an EC Plan-Neoluar $63 \times / 1.25$ oil objective and a AxioCam MRm Rev.2 camera.

\section{Lipid extraction and thin-layer chromatography}

Adult worms were washed 3 times with M9 buffer prior to sample collection via COPAS Biosort flow cytometry. For lipid analysis, 1,000 wild-type worms and 1,500 sams-1 mutant animals were collected. The samples were adjusted to a volume of $50 \mu \mathrm{l}$ and stored at $-80{ }^{\circ} \mathrm{C}$ until further processing. Lipids were extracted through methyl-tertbutyl ether (MTBE) extraction according to the protocol of Matyash et al. (Matyash et al. 2008). The modified protocol applied for thin-layer chromatography analysis of C. elegans lipid extracts was recently reported by our group (Palgunow et al. 2012). Briefly, the samples and standards were loaded onto Polygram silica gel G precoated TLC sheets. The TLC sheets were run in a 20:20:1 n-hexane/ diethyl ether/formic acid solvent mixture (for separation of neutral lipids) or using a 3:2:2:1 1-propanol/propionic acid/ chloroform/water solvent system (for separation of phospholipids). Lipid spots were stained for $20 \mathrm{~s}$ in a dip solution (10\% copper(II) sulfate, $8 \%$ phosphor acid, and $5 \%$ methanol) and heated for $20 \mathrm{~min}$ at $150{ }^{\circ} \mathrm{C}$. The lipid spots were then imaged with an Alphaimager HP for equal exposure times of $20 \mathrm{~s}$ and analyzed using FluorChem software. For all measurements, at least 3 biological replicates were analyzed.

Quantification of triacylglyceride and protein levels in colorimetric assays

To lyse worms, samples were suspended in $100 \mu \mathrm{l}$ of buffer (50 mM Tris pH 7.5, $150 \mathrm{mM} \mathrm{NaCl}, 1 \mathrm{mM}$ EDTA $\mathrm{pH}$ 8.0, 0.5 \% CHAPS) and homogenized with a Precellys ${ }^{\circledR} 24$ ( $1.4 \mathrm{~mm}$ ceramic beads; $\left.1 \times 6,500 \mathrm{rpm}\right)$. The resultant cell debris was pelleted via centrifugation (20 min; 14,000 rpm; $4{ }^{\circ} \mathrm{C}$ ), and the supernatants were transferred to new tubes and employed for colorimetric assays. The TAG content was determined using an enzymatic assay kit (Analyticon Diagnostic, Lichtenfels, Germany) with a separate TAG standard (BioCat, Heidelberg, Germany) according to the manufacturer's instructions. A bicinchoninic acid (BCA) assay kit (Pierce protein assay kit, Thermo Fisher Scientific Inc., Rockford, USA) was used for protein quantification, with BSA as a standard. Three biological replicates for each strain and each condition were analyzed in duplicate for TAG and protein determination.

Total RNA isolation and microarray-based gene expression analysis

A total of 2,000-3,500 adult worms were harvested, washed 3 times with M9 buffer, and resuspended in $350 \mu \mathrm{l}$ of RLT buffer (RNeasy Mini Kit, QIAGEN, Hilden, Germany). Worm homogenization was achieved with a Precellys ${ }^{\circledR} 24$ and through additional disruption using QIAshredder spin columns (QIAGEN, Hilden, Germany). The RNAeasy Mini Kit was employed for total RNA isolation, including on-column DNA digestion (RNasefree DNase Set; QIAGEN, Hilden, Germany), according to the manufacturer's instructions. The quality and yield of the extracted RNA were assessed spectrophotometrically (BioPhotometer, Eppendorf, Hamburg, Germany). Labeling, hybridization, and processing of the cRNA were 
performed by Source BioScience (imaGenes, Berlin, Germany). A customized Agilent gene expression microarray containing 61,643 oligos was employed for expression analysis. After quantile normalization, each dataset contained gene expression values for 26,843 genes. Gene expression data were derived from 3 biological replicates for each treatment group. The fold changes in expression intensities were calculated from the average gene expression value of each gene and represent the mutant-to-wild-type ratio.

\section{Statistical analysis}

Statistical analysis was performed with Microsoft Excel (2003) and GraphPad Prism (Version 4.0). Unless otherwise noted, the data represent the mean \pm SEM of at least 3 independent experiments. Significance was calculated using an unpaired two-tailed $t$ test. Welch's correction was applied if the variances were different. Differences were considered statistically significant at $p<0.05$ (*), $p<0.01$ $(* *)$, and $p<0.001(* * *)$.

\section{Results}

\section{Isolation of a sams-1 mutant}

From a collection of $C$. elegans mutants, we isolated $t 3210$ showing enlarged "bubbles" in its embryos (Fig. 1a). Whole-genome sequencing of the mutant combined with SNP mapping as well as Sanger sequencing and RFLP analysis of an amplified genomic PCR fragment revealed a point mutation in the $S$-adenosyl methionine synthetase 1 (sams-1) gene. At position X: 11966380, a cytosine is changed to a thymine, resulting in an A105V amino acid substitution in SAMS-1 (Fig. 1b). The sams-1(t3210) mutant was crossed five times against wild-type worms. The enlarged "bubbles" in mutant eggs displayed a recessive Mendelian inheritance pattern, which was strictly linked to a single locus, the $\mathrm{C} \rightarrow \mathrm{T}$ mutation in sams-1. Hemizygous sams-1(t3210) mutant males also showed enlarged "bubbles." In silico analysis of the resulting A105V substitution in SAMS-1 predicted an impairment of protein function (Fig. 1c, d). Higher arsenite-induced mortality of sams-1(t3210) confirmed the bioinformatics predictions (Fig. 1e). This phenotype was also observed in the mutant strain RB2240, harboring a 480-bp deletion allele (ok3033) of sams-1 (Fig. 1e). The sams-1(t3210) allele and sams-1(ok3033) do not complement each other. All of these findings provide strong evidence that the sams1(t3210) mutant allele harms the protein's function. This study investigated both the sams-1(t3210) allele and the deletion allele sams-1(ok3033). sams-1 mutants show reduced phosphatidylcholine levels and elevated fat storage

Phosphatidylcholine is a major component of membranes and is synthesized via two pathways. The Kennedy pathway consists of the phosphorylation of choline to generate phosphocholine, which is converted to $\mathrm{PC}$ via CDP-choline. Alternatively, the PEAMT route involves the stepwise SAM-dependent methylation of PE to PC. Because the synthesis of PC consumes substantial amounts of SAM (Chiang et al. 1996), which is produced by SAMS-1, PC levels could be reduced in sams-1 mutants. Thin-layer chromatography-based analysis of lipid extracts revealed that sams-1 adults indeed exhibited reduced PC levels, whereas PE content was not altered (Fig. 2a). Body size and progeny numbers were also markedly reduced in the sams-1 mutants (Fig. 2b, c), indicating reduced membrane formation caused by reduced PC levels. This result confirms a pioneer work from the Hansen group (Hansen et al. 2005). Because reduced synthesis of PC increases lipogenesis (Igal et al. 2001; van der Veen et al. 2012; Walker et al. 2011), TAG storage was examined in the sams-1 mutants. Accordingly, sams-1 mutants displayed higher TAG storage (Fig. 2d) and up-regulation of key genes contributing to the synthesis of fatty acids and TAG (Fig. 2e). Expression analysis of genes encoding enzymes for degradation of TAG revealed that the lipase 5 gene (lipl-5) is consistently up-regulated in sams-1 mutants (Table S1). Taken together, these results indicate that the sams- 1 mutants show reduced PC levels and an accumulation of TAG.

sams-1 mutants exhibit enlarged lipid droplets throughout their life cycle

LDs act as TAG storage compartments. They are surrounded by a PL monolayer mainly containing PC and PE (Bartz et al. 2007). Because the ratio between TAG and PC could be an important determinant of LD size (Krahmer et al. 2011; McFie et al. 2011; Xu et al. 2012), LDs were visualized in the sams-1 mutants through 3D fluorescence imaging. Adult sams-1 mutants formed enlarged intestinal LDs that dramatically differed from those observed in wild-type worms (Fig. 3a-c). The overlay between DIC and fluorescence images (Fig. 3, b3, c3, e3, f3) revealed that the "bubbles" of the mutant $t 3210$ are indeed enlarged lipid droplets. The authenticity of these large LDs was confirmed based on the localization of the ATGL-1-GFP fusion protein, which serves as an LD marker in C. elegans (Zhang et al. 2010), to the surface of LipidToxRed-stained LDs (Fig. 3d). In both the sams-1(t3210) (Fig. 3e, f) and the sams-1(ok3033) (not shown) strains, the large embryonic vacuoles were identified as enlarged LDs (Fig. 3e, f). A slight expansion of LDs was also observed in the larvae of sams-1 mutants (not shown). 
A

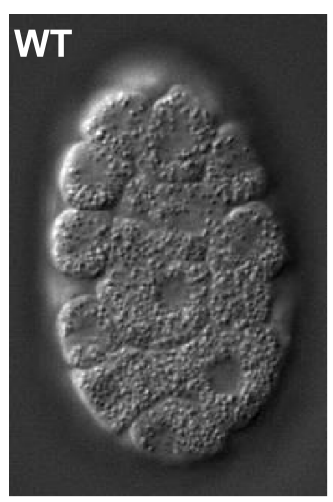

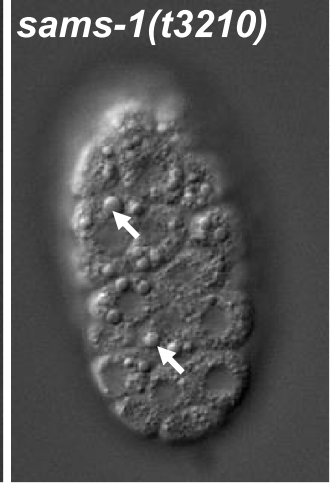

E

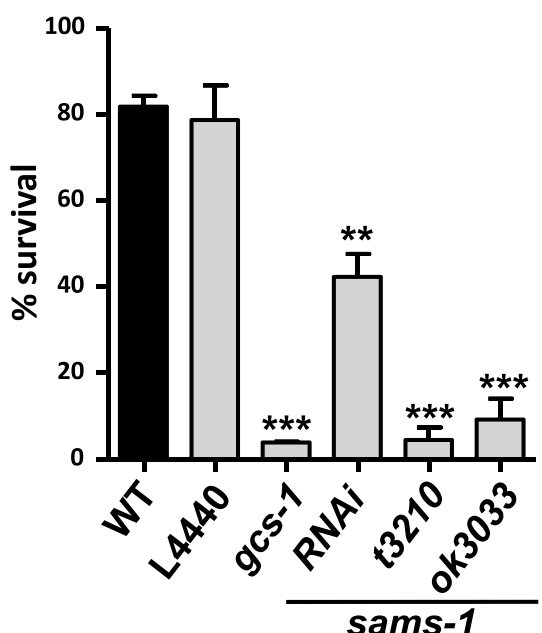

sams-1

B
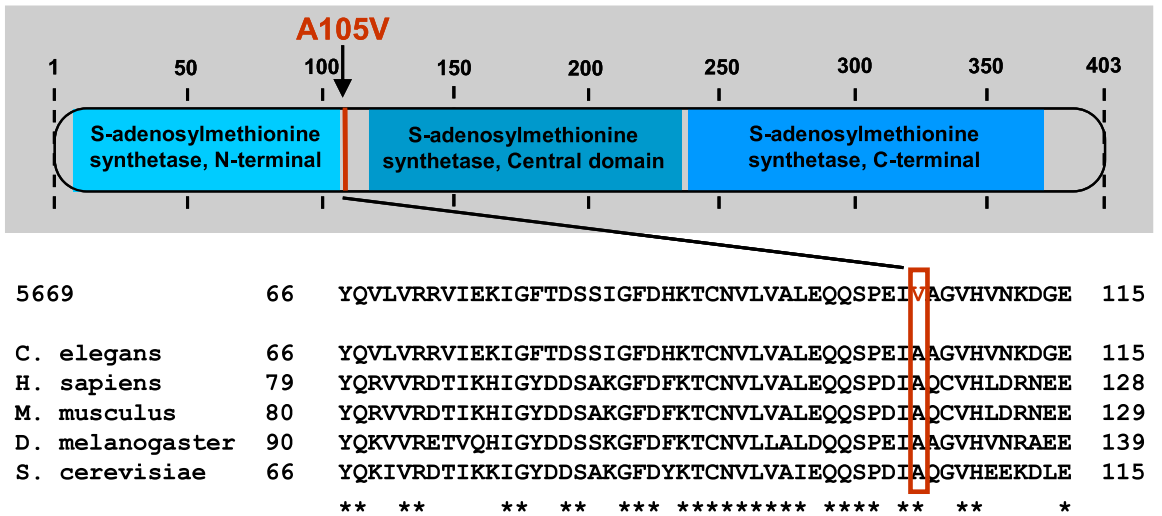

C

\begin{tabular}{l|c|c|c}
\multicolumn{1}{c|}{ algorithm } & Score & $\begin{array}{c}\text { Range } \\
\text { (tolerant }- \text { intolerant) }\end{array}$ & $\begin{array}{c}\text { predicted impact on } \\
\text { protein function }\end{array}$ \\
\hline $\begin{array}{l}\text { Grantham } \\
\text { Score }\end{array}$ & 64 & $0-\geq 150$ & $\begin{array}{c}\text { moderately } \\
\text { conservative }\end{array}$ \\
\hline $\begin{array}{l}\text { MutPred ** } \\
\text { polyphen }\end{array}$ & $p>0,05$ & P-values & no impact \\
$\begin{array}{l}\text { Po**,*** } \\
\text { SIFT } * * *\end{array}$ & 0,00 & $0-1$ & benign \\
\hline $\begin{array}{l}\text { Mutation } \\
\text { assessor }\end{array}$ & 4,68 & $1-0$ & intolerant \\
\hline
\end{tabular}

D

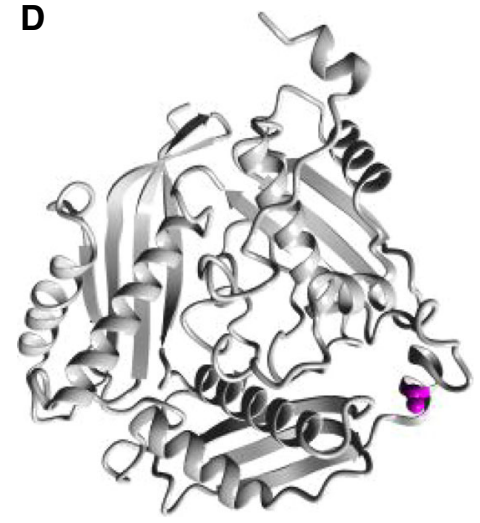

Fig. 1 Isolation of a $C$. elegans loss-of-function sams-1 mutant exhibiting enlarged embryonic "bubbles." a DIC images of embryos from wild-type (WT) worms and the sams-1(t3210) mutant, isolated by EMS mutagenesis. Enlarged lipid droplets in a sams-1(t3210) embryo are indicated by arrows. b Structure of SAMS-1. The 3 functional domains of SAMS-1 are indicated with blue boxes. The numbers represent amino acid residues in SAMS-1. The A105V substitution observed in the sams-1(t3210) mutant is depicted. Multiple sequence alignments of SAMS-1 are shown. c In silico analysis using web-based tools to predict the impact of the A105V substitution on the structure and function of SAMS-1. The predictions are based on single asterisks the physiochemical properties of the exchanged amino acids; double asterisks the probability of impairment of structural and functional protein features; and triple asterisks evolutionary conservation. d Model of the SAMS-1 crystal structure predicted by HOPE. The A105V substitution site is shown in magenta. e Survival rates (\% survival) of adult wild-type, sams-1 mutant, and sams-1 RNAi-treated worms. Worms fed a gcs-1 RNAi construct were used as positive controls. L4440, RNAi empty vector. Larvae were cultured on $4 \mathrm{mM}$ sodium arsenite NGM plates for $24 \mathrm{~h}$. Three independent experiments, each comprising 30 worms per strain, were performed. Significant differences compared to wild-type worms are indicated by asterisks and were calculated in unpaired $t$ tests $(* * p<0.01 ; * * * p<0.001)$ (color figure online) 

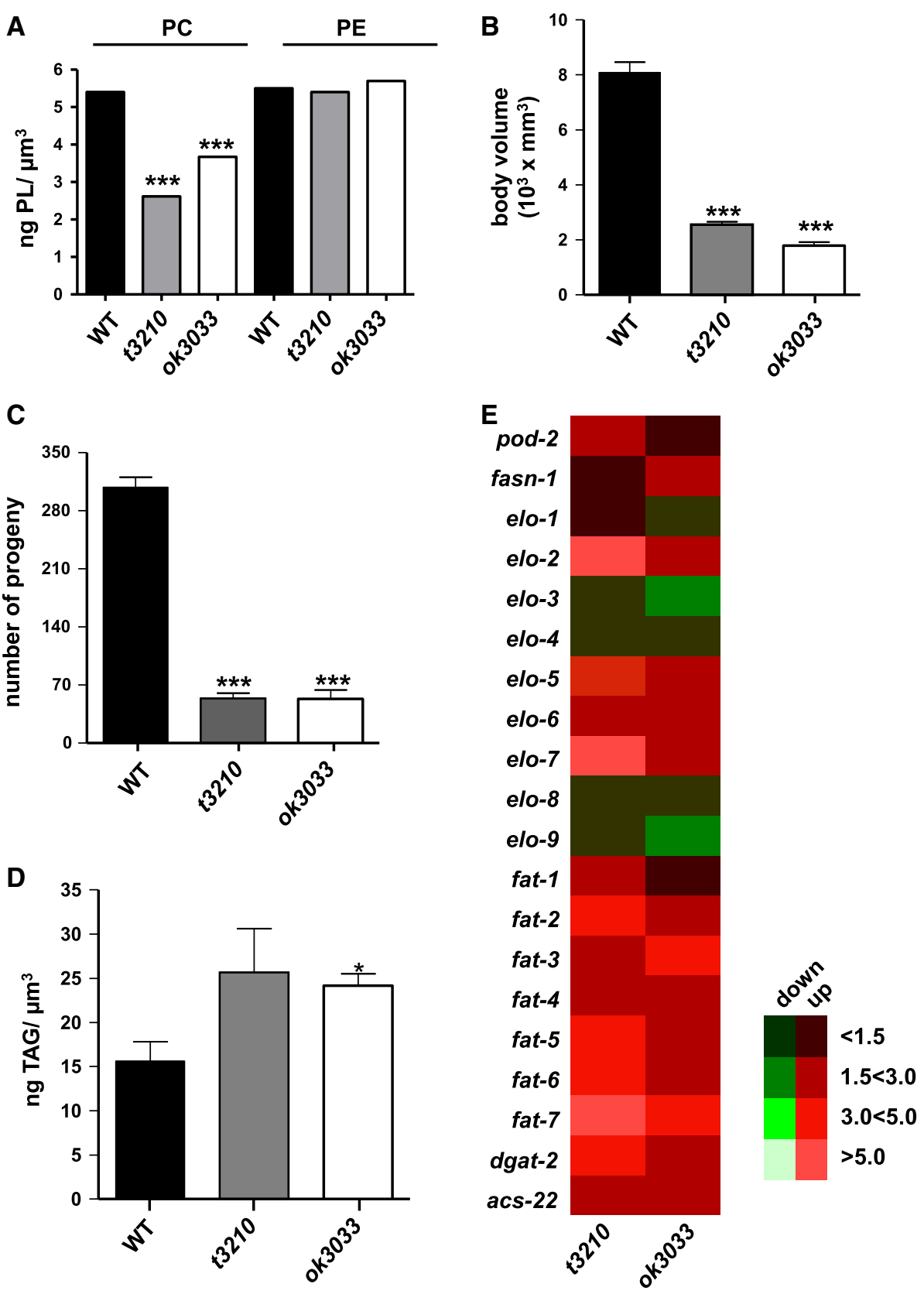

Fig. 2 Lipid analysis and differential expression of lipogenic genes in adult wild-type worms and sams-1 mutants. a TLC-based analysis of PC and PE in wild-type (WT) worms and the sams-1(t3210) and sams-1(ok3033) mutants. The levels of PC and PE were adjusted to the respective body volumes of the worms. b Body volumes of WT and sams-1 mutant worms. The data were derived from analysis of bright field microscopy images. Images of 10 worms per strain were analyzed in 3 independent experiments. c Number of progeny of WT and sams-1 mutant worms. The number of viable L4 progeny per worm was counted over the entire reproductive phase. Five worms per strain were analyzed in three independent experiments. d TLC-based

analysis of TAG in WT and sams-1 mutant worms. TAG levels were adjusted to the respective body volumes of the worms. e The expression of selected lipogenic genes was compared between WT and sams-1 mutant worms. Genes up-regulated in the sams-1 mutants are shown in red; down-regulated genes are shown in green. Fold changes in expression intensities were calculated from the average gene expression value of each gene and represent the mutant-to-wildtype ratio. Microarray-based gene expression data were derived from 3 independent experiments. a-d Significant differences were analyzed between WT worms and the respective sams- 1 mutant using unpaired $t$ tests $(* p<0.05 ; * * p<0.01 ; * * * p<0.001)$ 

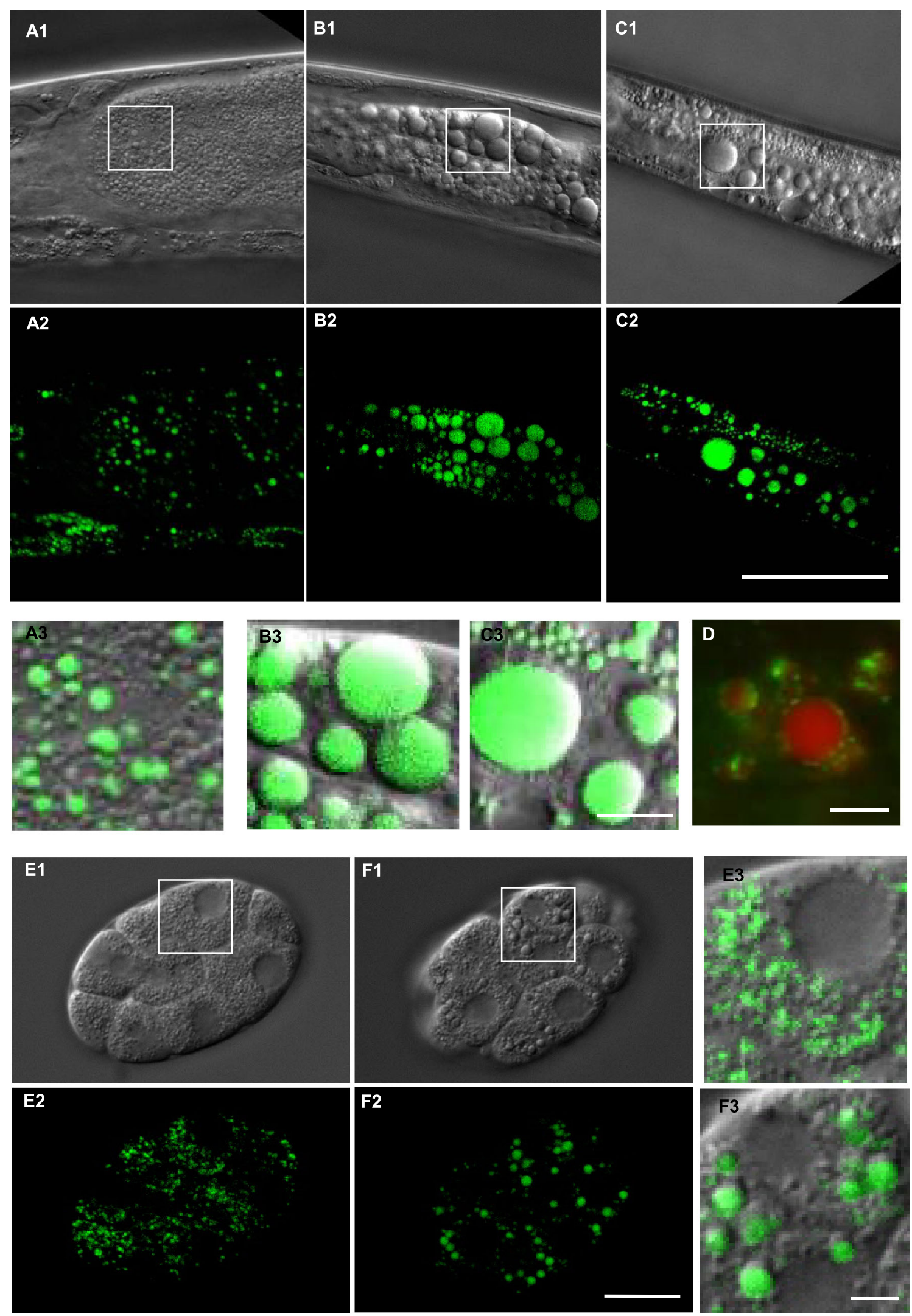
4Fig. 3 Lipid droplets in wild-type (WT) and sams-1 mutant worms visualized via vital BODIPY ${ }^{\mathrm{TM}}$ 493/503 fat staining. a-c DIC images $(\mathbf{a 1}, \mathbf{b 1}, \mathbf{c 1})$ and fluorescence images $(\mathbf{a 2}, \mathbf{b 2}, \mathbf{c 2})$ of the anterior intestines of adult WT worms (a1, a2) and adult sams-1(t3210) (b1, b2) and sams-1(ok3033) mutants (c1, c2) are shown. Detailed images of lipid droplets in WT worms (a3) and the sams-1(t3210) (b3) and sams-1(ok3033) (c3) mutants are shown as merged DIC and fluorescence images. d ATGL-1::GFP as a marker of lipid droplets in sams-1(t5669) mutants. Localization of ATGL-1::GFP on the surface of lipid droplets in sams-1(t5669) mutants expressing ATGL$1::$ GFP. Lipid droplets were stained with LipidToxRed. e, f DIC images $(\mathbf{e 1}, \mathbf{f 1})$ and fluorescence images $(\mathbf{e 2}, \mathbf{f 2})$ of 12-cell embryos of WT (e1, e2) and sams-1(t5669) mutants (f1, f2). Detailed images of lipid droplets in WT worms (e3) and sams-1(t3210) mutants (f3) are shown as merged DIC and fluorescence images. The scale bar represents $50 \mu \mathrm{m}$ in images $\mathbf{a} \mathbf{1} / \mathbf{2}, \mathbf{b} \mathbf{1} / \mathbf{2}$, and $\mathbf{c 1 / 2} ; 10 \mu \mathrm{m}$ in images $\mathbf{a 3}$, $\mathbf{b 3}$, and $\mathbf{c 3} ; 2 \mu \mathrm{m}$ in image $\mathbf{d} ; 20 \mu \mathrm{m}$ in $\mathbf{e} \mathbf{1} / \mathbf{2}$ and $\mathbf{f} \mathbf{1} / \mathbf{2}$; and $2 \mu \mathrm{m}$ in images $\mathbf{e} \mathbf{3}$ and $\mathbf{f 3}$

Thus, sams-1 mutants exhibited enlarged lipid droplets throughout their life cycle.

sams-1 mutants exhibit increased anterior and posterior intestinal fat, mainly stored in large lipid droplets

Because the large LDs were mainly localized to the anterior and posterior parts of the intestine, these compartments were selected for quantification of the size and number of LDs in sams-1 mutants. Despite the different number and size distribution of $\mathrm{LD}$, the mean $L D$ volume was approximately twofold higher in the sams- 1 mutants than in wildtype worms (Fig. 4a, b). This difference was found in both regions of the intestine. Furthermore, the sams-1 mutants displayed a reduced number of LDs in the anterior intestine, whereas the number of LDs in the posterior intestine was not altered (Fig. 4c, d). Next, we calculated the total volume of all LDs within an intestinal segment. This value should approximate TAG storage. Indeed, the sams-1 mutants exhibited a greater total LD volume in both intestinal regions (Fig. 4e, f), thus confirming the higher total TAG levels detected in sams-1 mutants via thin-layer chromatography (Fig. 2d). Based on the obtained total LD volume and distribution of LD size, we found that sams-1 mutants store more than $50 \%$ (WT: $10 \%$ ) of their intestinal fat in large-sized LDs $\left(\geq 10 \mu \mathrm{m}^{3}\right)$ (Fig. 4g, h). Together, these findings indicate that sams-1 mutants accumulate fat in large lipid droplets localized in the anterior and posterior part of the intestine.

In response to starvation, sams- 1 mutants show reduced depletion of triacylglycerides and lipid droplets that localize to the anterior intestine

As shown in many organisms, including C. elegans (McKay et al. 2003; Van Gilst et al. 2005; Jo et al. 2009), starvation induces lipolysis of TAGs stored in LDs.
Because LD size is assumed to be an important determinant in regulating lipolysis efficiency (Nishino et al. 2008), we analyzed total TAG levels using a biochemical assay in sams-1 mutants before and after starvation. In response to starvation, wild-type worms retained about $22 \%(24 \mathrm{~h})$ and $6.7 \%(48 \mathrm{~h})$ of their initial TAG stores, whereas the sams-1 mutants retained up to $50 \%(24 \mathrm{~h})$ and $30 \%$ $(48 \mathrm{~h})$ of their initial TAG stores (Fig. 5a). Next, 3D fluorescence imaging was performed to analyze the depletion of LDs in response to starvation in the sams-1 mutants. After 24 or $48 \mathrm{~h}$ of starvation, wild-type worms retained about $37 \%$ or $21 \%$, respectively, of their initial total LD volume in the anterior intestine, whereas the sams-1 mutants retained up to $74 \%$ or $70 \%$, respectively, of their initial total LD volume in that region (Fig. 5b). In the posterior intestine, the sams-1 mutants display only a slight depletion of LDs in response to starvation (Fig. 5c). Finally, we determined the size distribution of LDs before and after starvation in wild-type worms and sams- 1 mutants. In response to starvation, the wild-type worms exhibited preferential reduction in medium $\left(2-\leq 5 \mu \mathrm{m}^{3}\right)$ and large LDs $\left(5-\leq 5 \mu \mathrm{m}^{3}\right.$ and $\left.>10 \mu \mathrm{m}^{3}\right)$ localized in the anterior intestine (Fig. $5 \mathrm{~d}-\mathrm{g}$ ). In the posterior intestine, the wild-type worms showed essentially no size-dependent breakdown of LDs in response to starvation. In contrast to the wild-type worms, the starved sams- 1 mutants conserved LDs localized in the anterior intestine and exhibited essentially no size-dependent breakdown of LDs (Fig. 5dg). Taken together, these findings indicate that sams- 1 mutants exhibit a generally impaired starvation-induced breakdown of fat stores, associated with a strikingly impaired depletion of LDs localized to the anterior intestine.

\section{Discussion}

SAMS-1 regulates homeostasis

between phosphatidylcholine and fat storage

In the present study, we found that sams- 1 mutants show reduced levels of PC, indicating that SAM-dependent methylation of phosphoethanolamine to generate phosphocholine (the PEAMT route) is important for the proper synthesis of PC. This was also found by two other groups (Li et al. 2011; Walker et al. 2011). Accordingly, depletion of the respective SAM-dependent phosphoethanolamine methyltransferases reduces PC levels in other organisms as well (Brendza et al. 2007; Li et al. 2011; Palavalli et al. 2006). In mammals, the analogous PEMT pathway accounts for approximately $30 \%$ of hepatic PC synthesis (Reo et al. 2002). In sams- 1 mutants, we found that reduced PC levels were linked to increased TAG storage and an 
Fig. 4 Analysis of lipid droplets in the anterior and posterior intestine of adult wildtype (WT) and sams-1 mutant worms. a-f Mean volume (a, b), number (c, d), and total volume $(\mathbf{e}, \mathbf{f})$ of LDs in the anterior $(\mathbf{a}, \mathbf{c}$, e) and the posterior $(\mathbf{b}, \mathbf{d}$,

f) intestine of WT worms and the sams-1(t3210) and sams1(ok3033) mutants. G, H)

Distribution of the total LD

volume of $\mathrm{LD}$ size classes $\left(<2,2-5,5-10,>10 \mu \mathrm{m}^{3}\right)$ in the anterior (g) and posterior

(h) intestine of WT worms and sams-1 mutants. LDs were visualized via BODIPY ${ }^{\mathrm{TM}}$ 493/503 fat staining. Images were analyzed using the $3 \mathrm{D}$ object counter plugin of ImageJ software. $\mathbf{a}-\mathbf{h}$ Data were derived from at least 10 individual worms from 3 independent experiments. Statistically significant differences were calculated between WT worms and the respective RNAi-treated mutant strains using unpaired $t$ tests $(* * p<0.01$

$* * * p<0.001)$
A

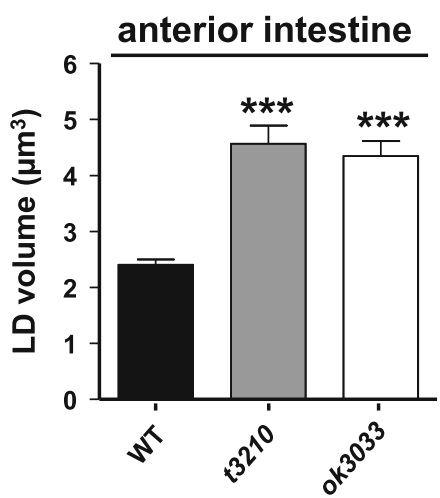

C

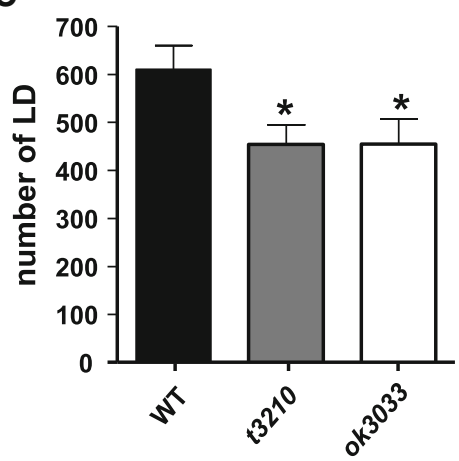

E

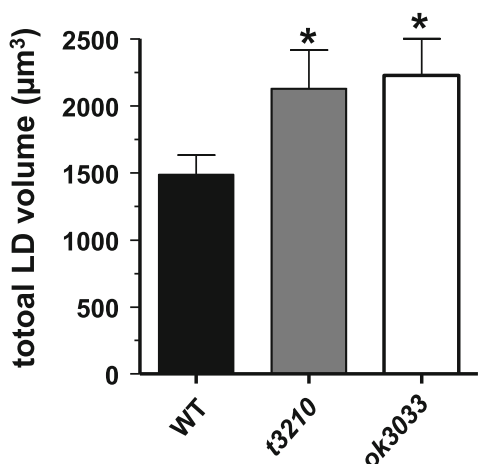

G

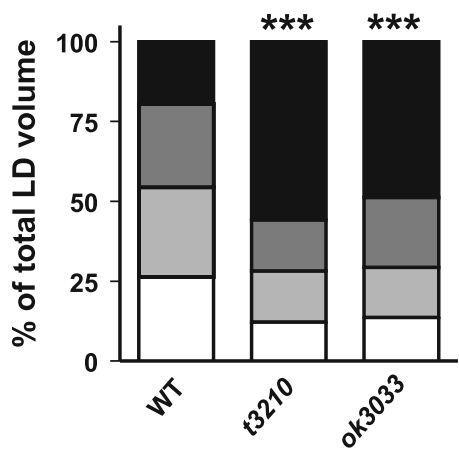

B

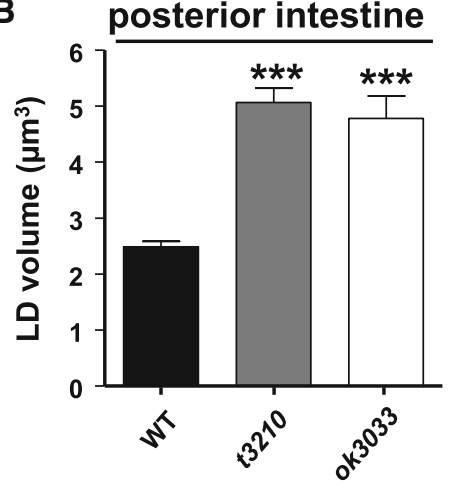

D

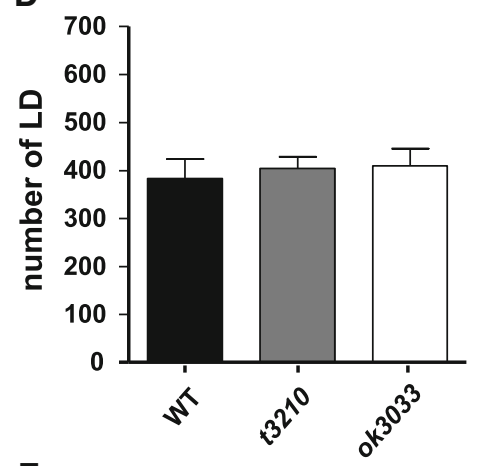

$\mathbf{F}$

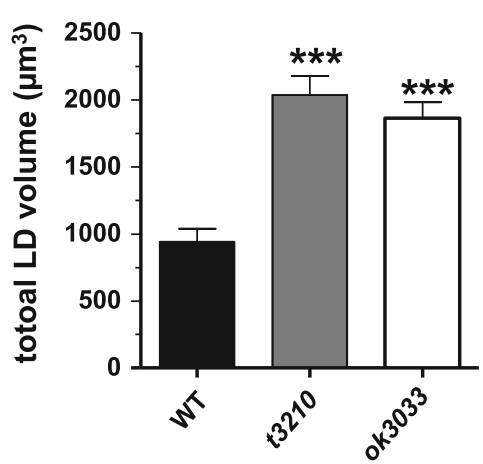

H

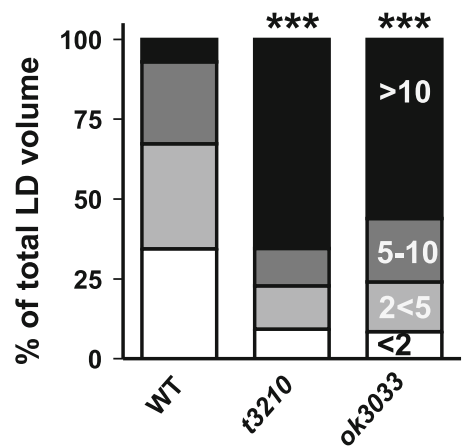

enhanced expression of several lipogenic genes targeted by the transcription factor SBP-1, which is the C. elegans ortholog of mammalian SREBP-1. In studies in C. elegans, mice, and cell lines, deficiency of PEMT/PEAMT pathway enzymes has been shown to elevate TAG storage (Jacobs et al. 2004; Walker et al. 2011; Lu et al. 2001; Li et al. 2011). All of these findings are in accordance with the current hypothesis that decreasing PC levels directly activates SBP-1, which induces TAG synthesis (Walker et al. 2011). With respect to the regulation of TAG degradation, 

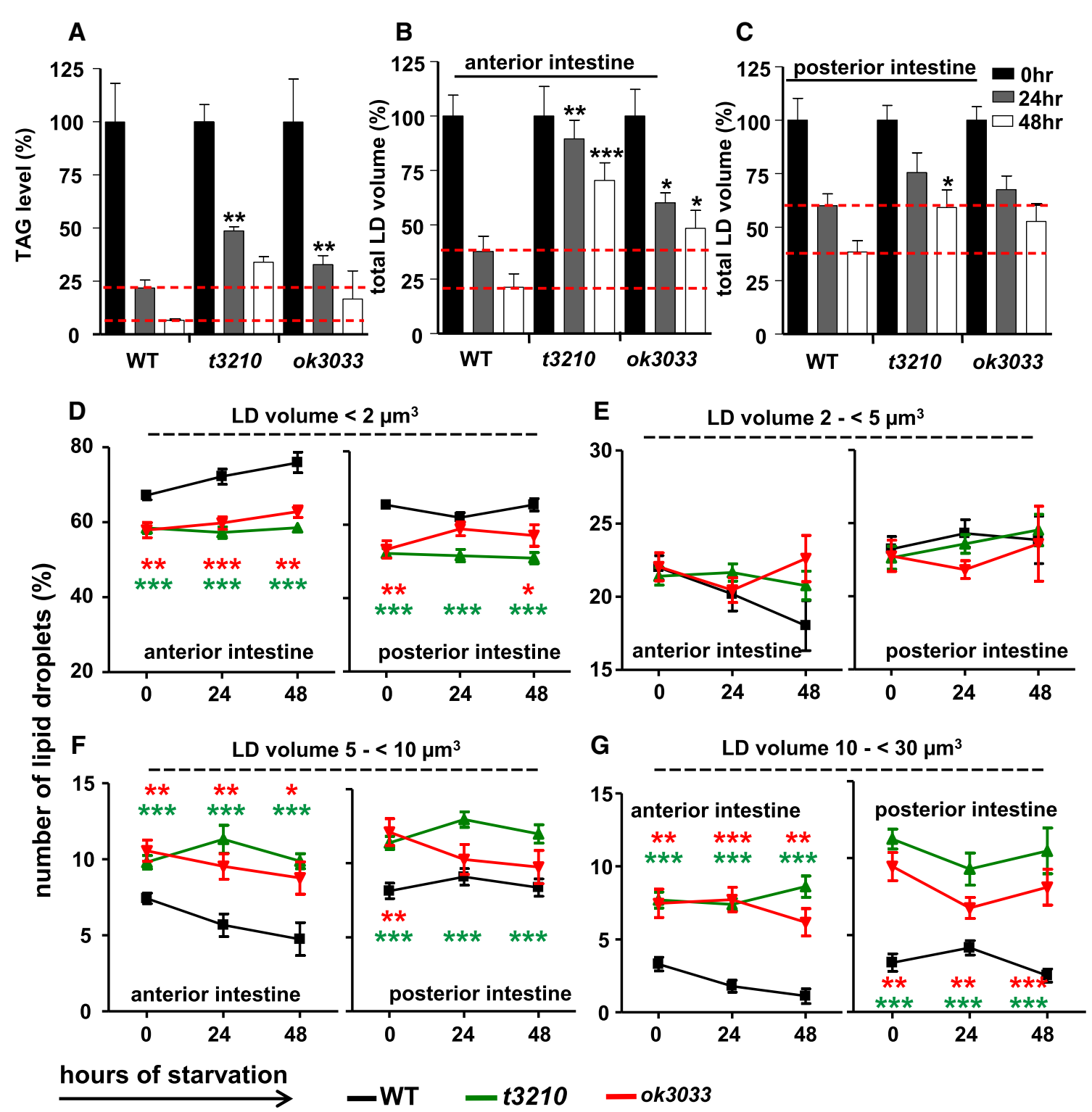

Fig. 5 Depletion of triacylglyceride and lipid droplet breakdown in response to starvation in wild-type (WT) worms and sams-1 mutants. a Enzymatically determined TAG levels in L4 larvae of WT worms and sams-1(t3210) and sams-1(ok3033) mutants exposed to starvation for 24 or $48 \mathrm{~h}$. b, c The total lipid droplet volume in the anterior (b) and posterior (c) intestine of L4 larvae ( $0 \mathrm{~h})$ of WT worms and the sams-1(t3210) and sams-1(ok3033) mutants exposed to starvation for 24 or $48 \mathrm{~h}$. d-g Number of LDs classified by size $(<2,2-5,5-10$, $\left.10-30 \mu \mathrm{m}^{3}\right)$ in L4 larvae $(0 \mathrm{~h})$ of WT worms and the sams-1(t3210)

our gene expression data are not consistent. The up-regulation of the lipase 5 gene (lipl-5) may represent a compensatory mechanism of the sams- 1 mutants.

As observed in mice and humans, a choline-deficient diet reduces PC levels and causes non-alcoholic steatohepatitis characterized by excess fat storage in the liver (Rinella and Green 2004; Zeisel et al. 1991). Thus, reduced PC levels and increased fat storage constitute a common phenomenon in $C$. elegans as well as in mammals. The and sams-1(ok3033) mutants in response to starvation (24 or $48 \mathrm{~h})$. The analyzed LDs were localized to the anterior and posterior intestine. b-g LDs were visualized via BODIPY ${ }^{\text {TM }}$ 493/503 fat staining, and images were analyzed using the 3D object counter plugin of ImageJ software. Asterisks indicate significant differences between WT worms and the respective sams-1 mutant at a given time point, determined using unpaired $t$ tests with Welch's correction $(* p<0.05 ; * * p<0.01 ; * * * p<0.001)$

homeostasis between PC levels and fat storage is regulated by SAMS-1, which is a conserved enzyme involved in onecarbon metabolism.

SAMS-1 links phosphatidylcholine synthesis to lipid droplet size

We observed a marked expansion of LDs in the sams-1 mutants, with LD enlargement being intensified from the 
larval stage to adulthood. Enlargement of LD in SAMS-1 deficient worms was recently described ( $\mathrm{Li}$ et al. 2011; Walker et al. 2011). Worms passing through the L4 larvaeto-adult transition display dramatic germ cell proliferation, a marked extension of the gonadal arms, and gametogenesis, all of which are processes that consume large amounts of PC (Hubbard and Greenstein 2005). A connection between LD size and PC demand has been reported in several other studies, revealing that LD enlargement occurs via LD fusion upon inhibition of PC synthesis (Krahmer et al. 2011; Guo et al. 2008; Moessinger et al. 2011; Li et al. 2011; Walker et al. 2011). Fusion of LDs decreases their surface-to-volume ratio and enables rapid removal of excess membrane components (Murphy et al. 2010). Thus, it is conceivable that LD enlargement observed in sams-1 mutants is mediated by LD fusion. This hypothesis will be analyzed via 4D microscopy in the future. Interestingly, we also detected enlarged LDs in sams- 1 embryos. As we identified enlarged LDs very early in embryogenesis, the size of embryonic LDs might reflect a maternal PC deficiency.

\section{SAMS-1 controls the efficiency of lipolysis}

We found that the starvation-induced depletion of TAG stores was reduced in sams-1 mutants compared with wildtype worms. One hypothesis that might explain this finding is that the reduced surface area associated with a small number of large LDs, as observed in the sams-1 mutants, limits the accessibility of TAG-hydrolyzing lipases. Studies in worms, flies, and mice support this hypothesis. In $C$. elegans, a mutant deficient in peroxisomal $\beta$-oxidation showed enlarged intestinal LDs that were more resistant to lipase-triggered lipolysis (Zhang et al. 2010). In Drosophila, enlarged LDs due to defective PC synthesis were found to be more resistant to lipolysis (Krahmer et al. 2011; Guo et al. 2008). In mice, deletion of a gene encoding a fat-specific protein (FSP27) was shown to enhance lipolysis by promoting the formation of smaller LDs (Nishino et al. 2008). Lipolysis-derived fatty acids seem to be essential for cellular growth, as deletion of lipases associated with the surface of LDs causes a delay in cell-cycle entry and embryonic lethality (Kurat et al. 2009; Gronke et al. 2005). Thus, an inefficient supply of LDderived fatty acids may contribute to the reduced growth and reproduction of sams-1 mutants.

Astonishingly, in wild-type worms, we observed that starvation-induced LD breakdown was greater in the anterior than in the posterior intestine. This body regionspecific effect may represent LD subclasses differing in their susceptibility to lipolysis, e.g., to build long-term and short-term energy stores. Distinct LD subclasses have been described previously on the basis of LD-associated proteins
(Beller et al. 2006) and the rate of TAG incorporation (Kuerschner et al. 2008). In yeast, alteration of the PL composition in the membrane of supersized LDs reduces the levels of LD-resident lipases and attenuates the mobilization of neutral lipids (Fei et al. 2011). Based on this finding, we propose that sams- 1 mutants alter the specific membrane composition and protein coat of LDs, which leads to reduced lipolysis efficiency, especially in the anterior intestine. This hypothesis will be tested in the future using proteomic approaches.

\section{SAMS-1 deficiency mimics dietary restriction}

Dietary restriction (DR) is an environmental intervention that is characterized by a reduced food intake without inducing malnutrition (Masoro 2005). It has been shown in both $C$. elegans and other species that DR increases lifespan, reduces body size and fertility, enlarges LDs, and protects against proteotoxicity (Palgunow et al. 2012; Greer and Brunet 2009). Interestingly, these phenotypes have also been observed in SAMS-1-deficient organisms, as shown here and in other studies (Ching et al. 2010; Hansen et al. 2005; Li et al. 2011; Steinkraus et al. 2008; Tamiya et al. 2013; Walker et al. 2011). In the eat-2 mutant, which is a genetic model of DR, sams-1 RNAi does not further extend lifespan (Hansen et al. 2005). Additionally, inhibition of sams- 1 down-regulates a DRresponsive gene $(d r r-2)$ necessary for DR-mediated longevity (Ching et al. 2010). These findings indicate that sams-1 is necessary for DR-mediated effects. They also indicate that DR reduces SAMS-1 activity and subsequent SAM production. Accordingly, restricted intake of methionine, an essential amino acid and precursor for SAM synthesis, reduces SAM production and prolongs lifespan in rodents (Orentreich et al. 1993). Because folic acid and vitamin B12 are also involved in the production of SAM, it is conceivable that restriction of these nutrients might mimic dietary restriction as well. In agreement, a study in rats showed that vitamin B12 deficiency causes increases in fatty acid synthesis (Matlib et al. 1979). Thus, the activity of SAMS-1 and subsequent SAM levels may represent a critical gauge of nutrient availability. This hypothesis is supported by a recent study carried out in yeast (Sutter et al. 2013) and was also formulated by the Hansen group (Hansen et al. 2005). Recently, it has been proposed that acdh-1 is an important nutrient sensor (MacNeil et al. 2013). Based on our gene expression, we expected that this gene has only a minor role for the mobilization of fat in the sams-1 mutant. On the other hand, Watson et al. (Watson et al. 2013) found in a sams- 1 mutant that $a c d h-1$ is important for metabolic connections between mitochondrial enzymes involved in amino acid metabolism, the TCA cycle, and the dietary response. 


\section{Conclusion}

In conclusion, we propose that SAMS-1-dependent synthesis of phosphatidylcholine via the PEMT pathway is crucial for proper lipogenesis, maintenance of small lipid droplets, and efficient depletion of a subset of lipid droplets. Given the importance of lipid metabolism for fundamental cellular processes, we propose that the physiological function of SAMS-1 is limitation of fat storage to ensure proper growth and reproduction.

Acknowledgments We thank Astrid Reinke for high throughput plating and Cathrin Struck for excellent strain processing. This work was supported by the Deutsche Forschungsgemeinschaft (RS) and by a grant from the German Ministry of Education and Science (FD).

Conflict of interest None.

\section{References}

Anand P, Cermelli S, Li Z, Kassan A, Bosch M, Sigua R, Huang L, Ouellette AJ, Pol A, Welte MA, Gross SP (2012) A novel role for lipid droplets in the organismal antibacterial response. Elife 1:e00003. doi:10.7554/eLife.00003

Bartz R, Li WH, Venables B, Zehmer JK, Roth MR, Welti R, Anderson RG, Liu P, Chapman KD (2007) Lipidomics reveals that adiposomes store ether lipids and mediate phospholipid traffic. J Lipid Res 48(4):837-847. doi:10.1194/jlr.M600413JLR200

Beller M, Riedel D, Jansch L, Dieterich G, Wehland J, Jackle H, Kuhnlein RP (2006) Characterization of the Drosophila lipid droplet subproteome. Mol Cell Proteomics 5(6):1082-1094. doi:10.1074/mcp.M600011-MCP200

Brendza KM, Haakenson W, Cahoon RE, Hicks LM, Palavalli LH, Chiapelli BJ, McLaird M, McCarter JP, Williams DJ, Hresko MC, Jez JM (2007) Phosphoethanolamine N-methyltransferase (PMT-1) catalyses the first reaction of a new pathway for phosphocholine biosynthesis in Caenorhabditis elegans. Biochem J 404(3):439-448. doi:10.1042/BJ20061815

Brenner S (1974) The genetics of Caenorhabditis elegans. Genetics 77(1):71-94

Chiang PK, Gordon RK, Tal J, Zeng GC, Doctor BP, Pardhasaradhi K, McCann PP (1996) S-Adenosylmethionine and methylation. FASEB J 10(4):471-480

Ching TT, Paal AB, Mehta A, Zhong L, Hsu AL (2010) drr-2 encodes an eIF4H that acts downstream of TOR in diet-restrictioninduced longevity of C. elegans. Aging Cell 9(4):545-557. doi:10.1111/j.1474-9726.2010.00580.x

Davis MW, Hammarlund M, Harrach T, Hullett P, Olsen S, Jorgensen EM (2005) Rapid single nucleotide polymorphism mapping in $C$. elegans. BMC Genom 6:118. doi:10.1186/1471-2164-6-118

Doitsidou M, Poole RJ, Sarin S, Bigelow H, Hobert O (2010) C. elegans mutant identification with a one-step whole-genomesequencing and SNP mapping strategy. PLoS ONE 5(11): e15435. doi:10.1371/journal.pone.0015435

Farese RV Jr, Walther TC (2009) Lipid droplets finally get a little R-ES-P-E-C-T. Cell 139(5):855-860. doi:10.1016/j.cell.2009.11.005

Fei W, Zhong L, Ta MT, Shui G, Wenk MR, Yang H (2011) The size and phospholipid composition of lipid droplets can influence their proteome. Biochem Biophys Res Commun 415(3):455-462. doi:10.1016/j.bbrc.2011.10.091
Fujimoto T, Parton RG (2011) Not just fat: the structure and function of the lipid droplet. Cold Spring Harb Perspect Biol 3(3). doi:10. 1101/cshperspect.a004838

Greer EL, Brunet A (2009) Different dietary restriction regimens extend lifespan by both independent and overlapping genetic pathways in C. elegans. Aging Cell 8(2):113-127. doi:10.1111/j. 1474-9726.2009.00459.x

Gronke S, Mildner A, Fellert S, Tennagels N, Petry S, Muller G, Jackle H, Kuhnlein RP (2005) Brummer lipase is an evolutionary conserved fat storage regulator in Drosophila. Cell Metab 1(5):323-330. doi:10.1016/j.cmet.2005.04.003

Guo Y, Walther TC, Rao M, Stuurman N, Goshima G, Terayama K, Wong JS, Vale RD, Walter P, Farese RV (2008) Functional genomic screen reveals genes involved in lipid-droplet formation and utilization. Nature 453(7195):657-661. doi:10.1038/nature06928

Hansen M, Hsu AL, Dillin A, Kenyon C (2005) New genes tied to endocrine, metabolic, and dietary regulation of lifespan from a Caenorhabditis elegans genomic RNAi screen. PLoS Genet 1(1):119-128. doi:10.1371/journal.pgen.0010017

Hellerer T, Axang C, Brackmann C, Hillertz P, Pilon M, Enejder A (2007) Monitoring of lipid storage in Caenorhabditis elegans using coherent anti-Stokes Raman scattering (CARS) microscopy. Proc Natl Acad Sci USA 104(37):14658-14663. doi:10. 1073/pnas.0703594104

Herker E, Ott M (2011) Unique ties between hepatitis C virus replication and intracellular lipids. Trends Endocrinol Metab 22(6):241-248. doi:10.1016/j.tem.2011.03.004

Hubbard EJA, Greenstein D (2005) Introduction to the germ line. In: Community TCeR (ed) WormBook. doi:10.1895/wormbook.1. 18.1

Igal RA, Caviglia JM, de Gomez Dumm IN, Coleman RA (2001) Diacylglycerol generated in $\mathrm{CHO}$ cell plasma membrane by phospholipase $\mathrm{C}$ is used for triacylglycerol synthesis. J Lipid Res 42(1):88-95

Jacobs RL, Devlin C, Tabas I, Vance DE (2004) Targeted deletion of hepatic CTP:phosphocholine cytidylyltransferase alpha in mice decreases plasma high density and very low density lipoproteins. J Biol Chem 279(45):47402-47410. doi:10.1074/jbc.M404027200

Jo H, Shim J, Lee JH, Lee J, Kim JB (2009) IRE-1 and HSP-4 contribute to energy homeostasis via fasting-induced lipases in C. elegans. Cell Metab 9(5):440-448. doi:10.1016/j.cmet.2009. 04.004

Kamath RS, Ahringer J (2003) Genome-wide RNAi screening in Caenorhabditis elegans. Methods 30(4):313-321

Klapper M, Ehmke M, Palgunow D, Bohme M, Matthaus C, Bergner G, Dietzek B, Popp J, Doring F (2011) Fluorescence-based fixative and vital staining of lipid droplets in Caenorhabditis elegans reveal fat stores using microscopy and flow cytometry approaches. J Lipid Res 52(6):1281-1293. doi:10.1194/jlr.D011940

Krahmer N, Guo Y, Wilfling F, Hilger M, Lingrell S, Heger K, Newman HW, Schmidt-Supprian M, Vance DE, Mann M, Farese RV Jr, Walther TC (2011) Phosphatidylcholine synthesis for lipid droplet expansion is mediated by localized activation of CTP: phosphocholine cytidylyltransferase. Cell Metab 14(4):504-515. doi:10.1016/j.cmet.2011.07.013

Kuerschner L, Moessinger C, Thiele C (2008) Imaging of lipid biosynthesis: how a neutral lipid enters lipid droplets. Traffic 9(3):338-352. doi:10.1111/j.1600-0854.2007.00689.x

Kurat CF, Wolinski H, Petschnigg J, Kaluarachchi S, Andrews B, Natter K, Kohlwein SD (2009) Cdk1/Cdc28-dependent activation of the major triacylglycerol lipase $\mathrm{Tgl} 4$ in yeast links lipolysis to cell-cycle progression. Mol Cell 33(1):53-63. doi:10. 1016/j.molcel.2008.12.019

Li Y, Na K, Lee HJ, Lee EY, Paik YK (2011) Contribution of sams-1 and pmt-1 to lipid homoeostasis in adult Caenorhabditis elegans. J Biochem 149(5):529-538. doi:10.1093/jb/mvr025 
Li Z, Thiel K, Thul PJ, Beller M, Kuhnlein RP, Welte MA (2012) Lipid droplets control the maternal histone supply of Drosophila embryos. Curr Biol 22(22):2104-2113. doi:10.1016/j.cub.2012.09.018

Lu SC, Alvarez L, Huang ZZ, Chen L, An W, Corrales FJ, Avila MA, Kanel G, Mato JM (2001) Methionine adenosyltransferase 1A knockout mice are predisposed to liver injury and exhibit increased expression of genes involved in proliferation. Proc Natl Acad Sci USA 98(10):5560-5565. doi:10.1073/pnas.091016398

MacNeil LT, Watson E, Arda HE, Zhu LJ, Walhout AJ (2013) Dietinduced developmental acceleration independent of TOR and insulin in C. elegans. Cell 153(1):240-252. doi:10.1016/j.cell. 2013.02.049

Masoro EJ (2005) Overview of caloric restriction and ageing. Mech Ageing Dev 126(9):913-922. doi:10.1016/j.mad.2005.03.012

Matlib MA, Frenkel EP, Mukherjee A, Henslee J, Srere PA (1979) Enzymatic properties of mitochondria isolated from normal and vitamin B12-deficient rats. Arch Biochem Biophys 197(2):388-395

Matyash V, Liebisch G, Kurzchalia TV, Shevchenko A, Schwudke D (2008) Lipid extraction by methyl-tert-butyl ether for highthroughput lipidomics. J Lipid Res 49(5):1137-1146. doi:10. 1194/jlr.D700041-JLR200

McFie PJ, Banman SL, Kary S, Stone SJ (2011) Murine diacylglycerol acyltransferase-2 (DGAT2) can catalyze triacylglycerol synthesis and promote lipid droplet formation independent of its localization to the endoplasmic reticulum. J Biol Chem 286(32):28235-28246. doi:10.1074/jbc.M111.256008

McKay RM, McKay JP, Avery L, Graff JM (2003) C elegans: a model for exploring the genetics of fat storage. Dev Cell 4(1): $131-142$

Moessinger C, Kuerschner L, Spandl J, Shevchenko A, Thiele C (2011) Human lysophosphatidylcholine acyltransferases 1 and 2 are located in lipid droplets where they catalyze the formation of phosphatidylcholine. J Biol Chem 286(24):21330-21339. doi:10. 1074/jbc.M110.202424

Murphy S, Martin S, Parton RG (2010) Quantitative analysis of lipid droplet fusion: inefficient steady state fusion but rapid stimulation by chemical fusogens. PLoS ONE 5(12):e15030. doi:10. 1371/journal.pone.0015030

Nishino N, Tamori Y, Tateya S, Kawaguchi T, Shibakusa T, Mizunoya W, Inoue K, Kitazawa R, Kitazawa S, Matsuki Y, Hiramatsu R, Masubuchi S, Omachi A, Kimura K, Saito M, Amo T, Ohta S, Yamaguchi T, Osumi T, Cheng J, Fujimoto T, Nakao H, Nakao K, Aiba A, Okamura H, Fushiki T, Kasuga M (2008) FSP27 contributes to efficient energy storage in murine white adipocytes by promoting the formation of unilocular lipid droplets. J Clin Invest 118(8):2808-2821. doi:10.1172/JCI34090

Orentreich N, Matias JR, DeFelice A, Zimmerman JA (1993) Low methionine ingestion by rats extends life span. J Nutr 123(2): 269-274

Palavalli LH, Brendza KM, Haakenson W, Cahoon RE, McLaird M, Hicks LM, McCarter JP, Williams DJ, Hresko MC, Jez JM (2006) Defining the role of phosphomethylethanolamine $\mathrm{N}$-methyltransferase from Caenorhabditis elegans in phosphocholine biosynthesis by biochemical and kinetic analysis. Biochemistry 45(19):6056-6065. doi:10.1021/bi060199d

Palgunow D, Klapper M, Doring F (2012) Dietary restriction during development enlarges intestinal and hypodermal lipid droplets in Caenorhabditis elegans. PLoS ONE 7(11):e46198. doi:10.1371/ journal.pone. 0046198

Reo NV, Adinehzadeh M, Foy BD (2002) Kinetic analyses of liver phosphatidylcholine and phosphatidylethanolamine biosynthesis using (13)C NMR spectroscopy. Biochim Biophys Acta 1580(2-3):171-188

Rinella ME, Green RM (2004) The methionine-choline deficient dietary model of steatohepatitis does not exhibit insulin resistance. J Hepatol 40(1):47-51
Salomon MP, Ostrow D, Phillips N, Blanton D, Bour W, Keller TE, Levy L, Sylvestre T, Upadhyay A, Baer CF (2009) Comparing mutational and standing genetic variability for fitness and size in Caenorhabditis briggsae and $C$. elegans. Genetics 183(2):685-692, 681SI-619SI. doi:10.1534/genetics.109.107383

Steinkraus KA, Smith ED, Davis C, Carr D, Pendergrass WR, Sutphin GL, Kennedy BK, Kaeberlein M (2008) Dietary restriction suppresses proteotoxicity and enhances longevity by an hsf-1dependent mechanism in Caenorhabditis elegans. Aging Cell 7(3):394-404. doi:10.1111/j.1474-9726.2008.00385.x

Sutter BM, Wu X, Laxman S, Tu BP (2013) Methionine inhibits autophagy and promotes growth by inducing the SAM-responsive methylation of PP2A. Cell 154(2):403-415. doi:10.1016/j. cell.2013.06.041

Tamiya H, Hirota K, Takahashi Y, Daitoku H, Kaneko Y, Sakuta G, lizuka K, Watanabe S, Ishii N, Fukamizu A (2013) Conserved SAMS function in regulating egg-laying in C. elegans. J Recept Signal Transduct Res 33(1):56-62. doi:10.3109/10799893.2012. 756896

van der Veen JN, Lingrell S, Vance DE (2012) The membrane lipid phosphatidylcholine is an unexpected source of triacylglycerol in the liver. J Biol Chem 287(28):23418-23426. doi:10.1074/jbc. M112.381723

Van Gilst MR, Hadjivassiliou H, Yamamoto KR (2005) A Caenorhabditis elegans nutrient response system partially dependent on nuclear receptor NHR-49. Proc Natl Acad Sci USA 102(38):13496-13501. doi:10.1073/pnas.0506234102

Walker AK, Jacobs RL, Watts JL, Rottiers V, Jiang K, Finnegan DM, Shioda T, Hansen M, Yang F, Niebergall LJ, Vance DE, Tzoneva M, Hart AC, Naar AM (2011) A conserved SREBP-1/ phosphatidylcholine feedback circuit regulates lipogenesis in metazoans. Cell 147(4):840-852. doi:10.1016/j.cell.2011.09.045

Walther TC, Farese RV Jr (2012) Lipid droplets and cellular lipid metabolism. Annu Rev Biochem 81:687-714. doi:10.1146/ annurev-biochem-061009-102430

Watson E, MacNeil LT, Arda HE, Zhu LJ, Walhout AJ (2013) Integration of metabolic and gene regulatory networks modulates the C. elegans dietary response. Cell 153(1):253-266. doi:10. 1016/j.cell.2013.02.050

Xu N, Zhang SO, Cole RA, McKinney SA, Guo F, Haas JT, Bobba S, Farese RV Jr, Mak HY (2012) The FATP1-DGAT2 complex facilitates lipid droplet expansion at the ER-lipid droplet interface. J Cell Biol 198(5):895-911. doi:10.1083/jcb. 201201139

Zechner R, Kienesberger PC, Haemmerle G, Zimmermann R, Lass A (2009) Adipose triglyceride lipase and the lipolytic catabolism of cellular fat stores. J Lipid Res 50(1):3-21. doi:10.1194/jlr. R800031-JLR200

Zeisel SH, Da Costa KA, Franklin PD, Alexander EA, Lamont JT, Sheard NF, Beiser A (1991) Choline, an essential nutrient for humans. FASEB J 5(7):2093-2098

Zhang SO, Box AC, Xu N, Le Men J, Yu J, Guo F, Trimble R, Mak HY (2010) Genetic and dietary regulation of lipid droplet expansion in Caenorhabditis elegans. Proc Natl Acad Sci USA 107(10):4640-4645. doi:10.1073/pnas.0912308107

Zhang Y, Zou X, Ding Y, Wang H, Wu X, Liang B (2013) Comparative genomics and functional study of lipid metabolic genes in Caenorhabditis elegans. BMC Genom 14:164. doi:10. 1186/1471-2164-14-164

Zimmermann R, Strauss JG, Haemmerle G, Schoiswohl G, BirnerGruenberger R, Riederer M, Lass A, Neuberger G, Eisenhaber F, Hermetter A, Zechner R (2004) Fat mobilization in adipose tissue is promoted by adipose triglyceride lipase. Science 306(5700):1383-1386. doi:10.1126/science.1100747 